\title{
O ACOPLAMENTO ESTRUTURAL E O MOVIMENTO DO SANEAMENTO BANCÁRIO NO BRASIL
}

\section{STRUCTURAL COUPLING AND THE MOVEMENT OF SANITATION BANKING IN BRAZIL}

\begin{abstract}
ANTÔNIO AUGUSTO CRUZ PORTO
Graduado em Direito pela Faculdade de Direito de Curitiba. Mestre em Direito Econômico e Socioambiental pela Pontifícia Universidade Católica do Paraná. Pós-graduado em Direito Civil e Empresarial pela PUCIPR e pela Escola Ministério Público do Paraná. Advogado em Curitiba/PR. Professor de Graduação. acporto83@gmail.com

CIBELE MERLIN TORRES

Procuradora Jurídica da Pontifícia Universidade Católica do Paraná (PUCPR) e dos Colégios do Grupo Marista. Graduada em Direito pela Pontifícia Universidade Católica do Paraná. Mestre em Direitos Fundamentais e Democracia pela UNIBRASIL. cibeletorres@grupomarista.org.br
\end{abstract}

\begin{abstract}
RESUMO
Visitando um momento específico da história políticoeconômica nacional na década de 1990, pretende-se compreender em que medida e sob quais circunstâncias o sistema jurídico brasileiro observou os ruídos externos (advindos de outras áreas) e, a partir de processos de filtragem internas, foi capaz de modificar-se para legitimar inúmeras ações tendentes a estabilizar os programas de readequação monetária do País e a sanear diversas instituições financeiras em situação de insolvência ou déficit de liquidez. Nesse sentido, com base na Teoria Luhmanniana, tenta-se perscrutar as ideias de acoplamento estrutural e de autopioese dos sistemas, a fim de identificar, nesse contexto, a abertura do sistema jurídico brasileiro e as respectivas respostas às demandas orientadas por outros (sub)sistemas, especialmente o econômico.
\end{abstract}

Palavras-chave: abertura do sistema jurídico; acoplamento estrutural; saneamento do Sistema Financeiro Nacional.

\begin{abstract}
Visiting a specific time of national political-economic history in the 1990s, seeks to understand to what extent and under what circumstances the Brazilian legal system observed the external noise (coming from other areas) and from internal filtering processes, was able to be modified to legitimize numerous actions intended to stabilize the monetary readjustment programs of the country and sanitize various financial institutions insolvent. Accordingly, based on the Luhmann Theory, attempts to scrutinize the ideas of structural coupling and autopioesis systems in order to identify, in this context, the opening of the Brazilian legal system and their responses to other-oriented demands systems, especially economic.
\end{abstract}

Keywords: opening of coupling; reorganization of National Financial System; structural coupling. 


\section{SUMÁRIO}

INTRODUÇAO; 10 ACOPLAMENTO ESTRUTURAL LUHMANNIANO; 2 A REESTRUTURAÇÃO BANCÁRIA DA DÉCADA DE 1990; 3 A ABERTURA DO SISTEMA JURÍDICO; CONCLUSÃO; REFERÊNCIAS.

\section{INTRODUÇÃO}

Em meados da década de 1990, o Brasil era uma turbulência política, social e econômica. Recém-saído do processo de impeachment do então Presidente Collor, o País tentava buscar uma reestruturação do sistema econômico, sôfrego com anos e mais anos de inflação estratosférica, baixo crescimento do Produto Interno Bruto e sequencial arrocho salarial.

O Sistema Financeiro Nacional igualmente passava por sensível remodelação. A partir da estagnação monetária com a implementação do Plano Real em 1994, muitas instituições financeiras fizeram realçar seus problemas gerenciais, administrativos e operacionais, desencadeando uma série de rupturas e de aberturas de procedimentos de intervenção e de liquidação extrajudicial, fundados na Lei 6.024/74.

0 fim da inflação, assim, além de permitir à população conhecer o real valor do dinheiro, sobretudo pela possibilidade de antever o efetivo poder de compra da moeda, revelou igualmente o novo rumo para o Sistema Financeiro do País, ao qual as instituições financeiras tiveram de se adaptar - e, por certo, as que não conseguiram, tanto privadas quanto públicasestaduais, foram submetidas a intervenções estatais diversas, seja mediante inauguração de procedimentos liquidatórios, seja por intermédio de ações compulsórias de reorganização societária.

Nesse contexto, o objetivo deste artigo é estabelecer um paralelo entre a Teoria do Acoplamento Estrutural, encapada pelo sociólogo alemãoNiklasLuhmann, e a abertura do sistema jurídico brasileiro da década de noventa do Século XX, a fim de compreender como e sob quais circunstâncias histórico-econômicas o ordenamento jurídico criou as condições de possibilidade para a reestruturação do sistema bancário nacional.

O marco-teórico previamente projetado pauta-se, portanto, na Teoria dos Sistemas, incialmente propugnada por Humberto Maturanae Francisco Varela e, posteriormente, alinhada à sociologia por Luhmann para compreender a divisão dos espectros sociais em diversos sistemas (sociais, políticos, econômicos, jurídicos etc.), objetivando depreender como o sistema jurídico interagiu com o sistema econômico a ponto de, abrindo-se cognitivamente e sem deixar de 
operar dentro de suas particularidades, possibilitar a criação de novos paradigmas legislativos internos.

Desta forma, este texto está estruturado entre três capítulos, complementados pela introdução e conclusão, a saber: (i) no primeiro, busca-se perscrutar os aspectos principais concernentes à teoria do acoplamento estrutural luhmanniana; (ii) no segundo, visita-se rapidamente a história do movimento de saneamento bancário do País na década de 1990; e, (iii) no terceiro, intenta-se verificar a abertura do sistema jurídico brasileiro ao meio econômico então vigente, bem assim identificar os processos legislativos que dele fizeram parte.

\section{ACOPLAMENTO ESTRUTURAL LUHMINNIANO}

A Teoria dos Sistemas delineada pelo sociólogo Niklas Luhmann propõe a existência de diversos sistemas sociais (jurídico, político, filosófico, econômico etc.), que se relacionam entre si, apoiando-se na ideia do sistema como diferença. Assim, "na sociologia, a Teoria dos Sistemas toma como ponto de partida um princípio de diferenciação: o sistema não é meramente uma unidade, mas uma diferença" ${ }^{1}$, de modo que, "para poder ser situado, um sistema (unidade) precisa ser diferenciado"” . A disparidade entre os sistemas, cuja verificação explica as suas respectivas autonomias, reside justamente no nível interno, ou seja, no modelo a partir do qual realizam suas operações ${ }^{3}$ (o sistema jurídico, por exemplo, trabalha a partir do binômio legal/ilegal; a filosofia pode laborar dentro da ideia do justo/injusto ou do ético/antiético).

Nesse sentido, Luhmann objetiva dividir a sociedade em fragmentos isolados dotados de uma lógica interna própria, os chamados sistemas sociais, dentro dos quais todos os outros (sub)sistemas se agrupam, cada qual funcionando autonomamente a partir de seus modos de operação peculiares. A autonomia dos sistemas é consequência do fechamento operacional (encerramento operativo) frente aos elementos do ambiente - que faz com que o sistema

\footnotetext{
${ }_{2}^{1}$ LUHMANN, Niklas. Introdução à Teoria dos Sistemas. Petropolis/RJ: Editora Vozes, 2009. p. 101.

${ }^{2}$ Idem.

3 "A categorização da autopoiesis assume como ponto de partida a questão radical da autonomia, já que define o sistema a partir de seus próprios elementos. Autonomia significa que somente a partir da operação do sistema é possível determinar o que lhe é relevante e, principalmente, o que the é indiferente. Consequentemente, o sistema não está condicionado a responder a todo dato ou estímulo proveniente do meio ambiente. Os sistemas não podem importar nenhuma operação a partir do meio." Ibidem, p. 120.
} 

SANEAMENTO BANCÁRIO NO BRASIL

dependa de sua própria organização para construção, transformação e desenvolvimento ${ }^{4}$-, bem como da delimitação de uma fronteira de diferenciação entre a parte e o todo, factível apenas por meio da autopoiese $e^{5}$.

Em tal ambiente, “os sistemas sociais geram e reproduzem seus próprios elementos de funcionamento sem a interferência ou influência de elementos externos”6. Isso não significa, contudo, que o sistema seja estritamente fechado e não identifique a existência do ambiente e suas respectivas alterações, mas, sim, que as informações externas são interiorizadas a partir de uma orientação interna própria (o dualismo legal/ilegal, exemplificativamente).

0 processo de seleção interior revela-se de significativa proeminência para a geração de elementos dentro do sistema - logo, para o seu constante desenvolvimento -, pois, como observa Rômulo Figueira Neves, é essa escolha seletiva que permite "ao sistema ampliar seu repertório de elementos e completar o processo comunicativo e o desenvolvimento cognitivo, ao mesmo tempo em que mantém sua autopoiese e seu fechamento operacional”7.

Por conta disso, identifica-se uma porosidade sistêmica ${ }^{8}$ que permite também a realização do mecanismo de acoplamento estrutural, traduzido na capacidade dos sistemas de absorver elementos de outros sistemas, após a seleção interna (filtragem), aumentando a complexidade de suas próprias operações, autorreproduzindo-se, sem, no entanto, perder a autonomia. Com efeito, “o acoplamento estrutural serve para que outros sistemas - que possuam conteúdos pertencentes também ao sistema jurídico - realizem trocas comunicativas" $"$.

\footnotetext{
${ }^{4}$ LUHMANN, Niklas. Introducción a lateoría de sistemas. Versão espanhola Javier Torres Nafarrate. México: Universidad Ibero Americana, 1996. p. 85.

${ }^{5}$ Etimologicamente, a palavra vem do Grego: autos (próprio) e poiesis(criação, produção). Segundo Luhmann, autopoiesissignifica "determinacióndel estado seguinte del sistema, a partir de lalimitación anterior a la que llególaoperación. Únicamente por médio de uma estructuración limitante um sistema adquierela suficiente dirección interna que haceposiblelaautorrepreducción." Idem.

6 NEVES, Rômulo Figueira. Acoplamento estrutural, fechamento operacional e processos sobrecomunicativos na teoria dos sistemas sociais de Niklas Luhmann. São Paulo, 2005. Dissertação de Mestrado (Mestrado em Sociologia) Universidade de São Paulo, p. 20.

${ }^{7}$ Ibidem, p. 25.

${ }^{8}$ No tocante ao termo 'abertura', este significa que os elementos externos são considerados, mas não in natura. O sistema os observa, os percebe e, caso deseje 'absorvê-los', os 'traduz' a partir de seu próprio meio de comunicação simbolicamente generalizado, para garantir sua autopoiese.

9 TRINDADE, André. Para entender Luhmann: e o direito como sistema autopoiético. Porto Alegre: Livraria do Advogado, 2008. p. 89.
} 

SANEAMENTO BANCÁRIO NO BRASIL

Há, portanto, a apropriação de informações do ambiente, e também de outros sistemas, por meio do mecanismo de acoplamento estrutural ${ }^{10}$ - a partir do conceito desenvolvido por NiklasLuhmann com base na teoria biológica de Humberto Maturana ${ }^{11}$ e Francisco Varela.

Segundo a teoria luhmanniana, o conceito de acoplamento estrutural especifica não poder haver nenhuma importação diretamente do ambiente (entorno) que sirva para manter o patrimônio de autopoiese de um sistema. Em outras palavras, o ambiente não pode determinar o estado interno do sistema em nenhuma circunstância, pois "um sistema não pode ser mais ou menos autônomo, mais ou menos autopoiético"12.

Marcelo Neves definiu acoplamento estrutural como "filtros que excluem certas influências e facilitam outras", os quais serviriam de promoção de influências e instigações recíprocas entre sistemas autônomos diversos, sem influir na autonomia peculiar dos sistemas, existindo, pois, uma relação concomitante de independência e de dependência entre os sistemas acoplados estruturalmente ${ }^{13}$. Por isso, a suspensão de um acoplamento estrutural pode acarretar o desaparecimento de um determinado sistema ${ }^{14}$. Nota-se, assim, uma relação de reciprocidade e não de simples dependência ${ }^{15}$, já que o acoplamento estrutural permite o desenvolvimento do próprio sistema.

10 "Pelo fechamento operativo dos sistemas, pode-se ter a impressão do isolamento dos sistemas. Ledo engano. Estão interligados pelos chamados acoplamentos estruturais (Maturana utiliza tal nomenclatura)". LIMA, Fernando Rister Sousa. Constituição Federal: acoplamento estrutural entre os sistemas político e jurídico. Revista Eletrônica de Direitos Fundamentais e Democracia da Unibrasil, Volume 4, 2008. p. 16.

${ }^{11}$ No entanto, a concepção luhmanniana da autopoiese não reflete o modelo biológico de Maturana, afastando-se deste "na medida em que nela se distinguem os sistemas constituintes de sentido (psíquicos e sociais) dos sistemas não constituintes de sentido (orgânicos e neurofisiológicos). Na teoria biológica da autopoiese, há, segundo Luhmann, uma concepção radical do fechamento, visto que, para a produção das relações entre sistema e ambiente, é exigido um observador fora do sistema, ou seja, um outro sistema." NEVES, Marcelo. Entre Themis e Leviatã: uma relação difícil. São Paulo: Martins Fontes, 2006. p. 61-62.

12 LUHMANN, Niklas. Introducción a lateoría de sistemas, p. 98. Tradução livre: “(...) un sistema no puede ser más o menos autónomo, más o menos autopoiético".

${ }_{13}^{13}$ NEVES, Marcelo. Transconstitucionalismo. São Paulo: Editora Martins Fontes, 2009. p. 35.

14 NEVES, Rômulo Figueira. Acoplamento estrutural, fechamento operacional e processos sobrecomunicativos na teoria dos sistemas sociais de Niklas Luhmann. 2005. 149 f. Dissertação (Mestrado em Sociologia) - Faculdade de Filosofia, Letras e Ciências Humanas, Universidade de São Paulo, São Paulo, 2005. fl. 57.

${ }^{15}$ No tocante à relação dependência/independência entre os sistemas, Fernando Rister Sousa Lima constata que “(...) mesmo com o fechamento operativo dos subsistemas e com a autonomia das operações, têm eles ligações entre si. São fechados em informação e abertos à energia. A forma de comunicar-se é pelas prestações", um exemplo seria a política e o direto, ou seja, "a política precisa do direito, e a recíproca é verdadeira; não sendo diferente à economia ou a qualquer outro sistema parcial. A 

SANEAMENTO BANCÁRIO NO BRASIL

Isso porque, quando há o chamado acoplamento estrutural, a aproximação de um sistema com o outro não representa somente uma irritação ou perturbação negativa (alopoiese), senão, sobretudo, uma ferramenta auxiliar de funcionamento das respectivas operações internas $^{16}$ (autopoiese). As desestabilizações causadas pelo contato entre sistemas não são necessariamente prejudiciais; ao contrário, permitem uma reação e um crescimento continuado, além de viabilizar uma diferenciação necessária e positiva entre os sistemas ${ }^{17}$.

Analisando os conceitos trazidos, pode-se - ainda que erroneamente, a uma primeira análise - dessumir-se que o acoplamento estrutural é algo sempre evidente e de fácil identificação. No entanto, não raro esta junção “permanece invisível para o sistema, pois não pode contribuir com a produção de seus elementos, e ele(a) pode ocorrer sem que o sistema perceba" ${ }^{18}$. Na verdade, é exatamente isso que torna o acoplamento estrutural compatível com a autopoiese, tanto que aquele somente pode interferir no sistema na medida em que não atente contra esta ${ }^{19}$.

Não se pode perder de vista, destarte, que os acoplamentos estruturais não têm o objetivo de estipular normas ou limitações na comunicação entre sistemas sociais, porém intuem unicamente provocar irritações, perturbações para que o sistema reaja, processe a informação e a importe, incorporando-a dentro de sua estrutura.

\section{A REESTRUTURAÇÃO BANCÁRIA BRASILEIRA DE 1990}

Aos olhos de hoje, não restam dúvidas de que o sistema bancário brasileiro galgou sensível evolução, tanto do ponto de vista da qualidade dos ativos, quanto da modernização das instituições financeiras e da própria capacidade do Banco Central do Brasil em monitorar, identificar e eventualmente intervir diretamente em bancos sob situação deficitária, fatores que

prestação fornecida pelo subsistema ao outro é um ato de reciprocidade". LIMA, Fernando Rister Sousa. Op. Cit., p. 12.

16 "Pelo acoplamento estrutural um sistema 'empresta' de um outro sistema, que é visto como parte do ambiente daquele primeiro, as estruturas necessárias para realizar as suas próprias operações”. NEVES, Rômulo Figueira. Acoplamento estrutural..., p. 54.

17 Observe-se, por oportuno, que "a função de reduzir a complexidade do mundo é tarefa dos sistemas sociais, realizada pelo alto grau de diferenciação comunicativa”. LIMA, Fernando Rister Sousa. Op. Cit., p. 06.

${ }^{18}$ NEVES, Rômulo Figueira. Acoplamento estrutural..., p. 55.

${ }^{19}$ LUHMANN, Niklas. Introducción..., p. 99/100. 
tendem a mitigar os riscos sistêmicos derivados das atuais operações financeiras, sabidamente multifacetárias e substancialmente interligadas ${ }^{20}$.

Essa inferência, no entanto, é resultado de um longo processo de luta pela estabilização monetária e, sem dúvida, de inúmeros percalços e arranhões sucedidos nas variadas ações (e tentativas de ações) visando à reestruturação do sistema bancário nacional, especialmente ocorridas em meados nos anos $1990^{21}$.

É consabido que o elevado grau de corrosão do poder aquisitivo das inúmeras moedas brasileiras, sobretudo nos idos de 1980 e na primeira metade dos anos 1990, maculava intensamente o desenvolvimento de diversos setores produtivos do País, mitigando igualmente o consumo e refreando incessantemente o crescimento econômico. Essa situação, no entanto, maquiava outro grave e complexo problema estrutural e administrativo de diversas instituições financeiras, que se utilizavam da inflação como forma de potencializar os lucros, sem, contudo, diversificar e modernizar suas operações.

Dentro desse contexto, Gilberto Tadeu Lima anota que "o sistema financeiro brasileiro, o maior e mais complexo na América Latina, teve sua dinâmica, em especial nas duas décadas anteriores a 1994, sensivelmente condicionada pelo crônico processo inflacionário que predominou no período"22. Na sua visão, o longo lapso temporal em que houve sequencial descontrole sobre o processo inflacionário "permitiu às instituições financeiras ganhos proporcionados por passivos não remunerados, tais como depósitos à vista e recursos em trânsito (floating), compensando eventuais ineficiências administrativas e perdas decorrentes de concessões de créditos de liquidação duvidosa" ${ }^{23}$, comprometendo, em consequência, a correta

\footnotetext{
${ }^{20}$ Registre-se o que assentou Niall Ferguson: “A história financeira é, em essência, o resultado da mutação institucional e da seleção natural. (...). Não somente novas formas de firmas financeiras estão proliferando: também novas formas de serviço e de ativo financeiros. (...). Em termos evolucionários, então, o setor de serviços financeiros parece ter passado através de uma explosão cambriana de vinte anos, com o florescimento das espécies existentes e o crescimento do número de novas espécies." FERGUSON, Niall. A ascensão do dinheiro: a história financeira do mundo. São Paulo: Planeta, 2009. p. 329.

${ }^{21}$ A jornalista Mirian Leitão, desnudando a saga dos inúmeros planos econômicos criados no País, comenta a importância de recontar a história a fim de que se possam extrair benefícios dessa experiência econômica: "O Plano Real foi construído com os acertos que o antecederam, e com a persistência que o sucedeu. Frequentemente se ouve que uma reforma política vai resolver tudo num passo de mágica. A ideia é sedutora, mas falsa. 0 próprio Plano Real não foi apenas a reforma monetária. Foi o estuário de várias mudanças e avanços que deram bases da moeda estável”. LEITÃO, Mirian. Saga Brasileira: a longa luta de um povo por sua moeda. Rio de Janeiro: Record, 2011. p. 443.

${ }_{22}$ LIMA, Gilberto Tadeu. Evolução Recente da Regulação Bancária no Brasil. In SOBREIRA, Rogério (Org.). Regulação Financeira e Bancária. São Paulo: Atlas, 2005. p.201.

${ }^{23}$ Idem.
} 

SANEAMENTO BANCÁRIO NO BRASIL

avaliação acerca da eficiência da gestão bancária e das qualidade dos produtos e serviços fornecidos pelas instituições bancárias.

Na mesma linha, Fábio Ulhoa Coelho relembra que, “até então, o processo contínuo de deterioração do poder aquisitivo da moeda possibilitava aos bancos auferirem ganhos, sem muitos esforços, por não estarem obrigados ao pagamento de correção monetária integral sobre a generalidade dos depósitos" 24 . Isso, pois, o lucro advindo do chamado "imposto inflacionário" permitia que as casas bancárias auferissem receitas desvinculadas de sua capacitação administrativa e gerencial e da própria qualidade dos produtos e serviços que ofereciam ao grande público, limitando-se a estruturar suas atividades em torno da captação de recursos de clientes - sobretudo advindos de depósitos não remunerados - com vistas a obter ganhos com a alta inflação monetária ${ }^{25}$.

Após a implementação do Plano Real e a estabilização da moeda, que redundou no equilíbrio do sistema e na estagnação dos sobressaltos inflacionários, os Bancos deixaram de colher esses dividendos. Fez-se notar, como corolário, a fragilidade do sistema bancário, desvelando graves problemas de gestão, fraudes e maquiagens contábeis ${ }^{26}$.

Assertivamente, Otávio Yazbek esclarece o assunto:

"Com o fim da inflação, muitas instituições perderam as chamadas receitas de floating, decorrentes da administração conjunta dos depósitos à vista não remunerados, feitos pelos clientes, e de outras operações. Da mesma maneira,

\footnotetext{
${ }^{24}$ COELHO, Fábio Ulhoa. Assunção de ativos e transferência de passivos na recuperação da empresa financeira: a reorganização externa. Revista de Direito Bancário e do Mercado de Capitais e da Arbitragem, São Paulo, ano 4, n 11, p. 39-47, jan./mar. 2001. p. 39.

25 "No Brasil, o setor financeiro prosperou tanto em tamanho quanto em rentabilidade, tendo sido apontada, muitas vezes, como conivente útil do processo inflacionário - crítica com certo fundamento, dada a forma da intermediação financeira no Brasil. As elevadas diferenças entre as taxas de juros pagas aos aplicadores e aquelas emprestadas, inclusive para o maior devedor, o Estado, representaram grande fonte de lucratividade para os bancos. Com o controle da inflação iniciado em 1994, o panorama existente não tardou a se alterar. Muitas instituições passaram a apresentar situações de insuficiência patrimonial e financeira. Logo, ficou patente a premência da reorganização societária no segmento financeiro, por um lado, e a emanação de um novo cabedal de regras e normas aplicáveis ao setor, por outro". SADDI, Jairo. O Poder e o Cofre: repensando o Banco Central. São Paulo: Textonovo, 1997. p. 214.

${ }^{26}$ Emílio Dantas comunga de idêntica visão e traz alguns números bastante relevantes a coonestar o pensamento: "Resultado da diferença entre a captação de recursos a custo praticamente zero, como recebimento de depósitos à vista ou recolhimento de tributos, e a aplicação desses recursos a taxas altas, o floating gerou R\$ 8,5 bilhões para os bancos em 1992, R\$ 11,5 bilhões em 1993 e R\$ 9 bilhões em 1994, reduzindo-se para R\$ 251 milhões já no primeiro semestre de 1995. Essa queda vertiginosa da principal fonte de lucros dos bancos alterou alguns aspectos da supervisão bancária". COSTA, Emílio Carlos Dantas. Supervisão Bancária: conceitos gerais. In SADDI, Jairo. Intervenção e liquidação no sistema financeiro nacional - 25 anos da Lei 6.024/74. São Paulo: Textonovo, 1999. p. 77.
} 

SANEAMENTO BANCÁRIO NO BRASIL

uma vez eliminadas as distorções até então existes, ficou evidenciada a fragilidade da estrutura patrimonial de boa parte das instituições financeiras não eram raros, desse modo, os problemas de má gestão, disfarçados pela reduzida transparência e pela contabilidade bancária" 27 .

Em adição, registre-se que "a abertura da econômica revelou o grau de ineficiência de vários setores domésticos, com reflexos na capacidade de recuperação de empréstimos concedidos pelos bancos"28. Fato é, nesse panorama, que o fim da inflação descontrolada - ou, ao menos, o estabelecimento programático de metas de inflação - implicou a necessidade de as instituições financeiras promoverem novas estratégias de atuação nos mercados sofisticados e de massa, novos modelos de gestão empresarial e novas políticas de condução interna de receitas e despesas $^{29}$. Foi assim que "para obtenção de resultados positivos as instituições financeiras passaram a depender mais de suas operações, quer sejam de tesouraria, quer sejam junto à clientela, e menos de meras captações de recursos a custo zero e repasse a taxas elevadas" 30 .

Nessa época, identificou-se "uma total incapacidade de nossas instituições financeiras em promover espontaneamente os ajustes necessários para sua sobrevivência nesse novo ambiente econômico" 31 . Por tal razão, “emergiram certos problemas de liquidez na indústria bancária”32, desencadeando a necessidade de intervenção do Estado, por meio do órgão regulador (Banco Central do Brasil), em inúmeras instituições financeiras, inclusive de grande porte, “impondo ao governo a necessidade de maior presença no cenário financeiro, além da adoção de normas legais e regulamentares mais rigorosas"33.

Revisita-se este fato histórico relevante: em um cenário econômico com 265 instituições financeiras, mais de 16 mil agências e 11 mil postos de atendimento, vários bancos quebraram, acarretando inúmeros prejuízos financeiros e sociais ao Sistema Financeiro Nacional ${ }^{34}$.

\footnotetext{
27 YAZBEK, Otávio. YAZBEK, Otávio. Regulação do Mercado Financeiro e de Capitais. 2. ed. Rio de Janeiro: Elsevier, 2009. p. 279.

${ }^{28}$ LIMA, Gilberto Tadeu. Op. Cit. In SOBREIRA, Rogério (Org.). Op. Cit., p.202.

29 Sobre o assunto, remete-se a: CARVALHO, Fernando J. Cardim de. Regulação Prudencial na Encruzilhada: depois de Basiléia II, o Dilúvio? In PAULA, Luiz Fernando de; OREIRO, José Luís (Org). Sistema Financeiro: uma análise do setor bancário brasileiro. Rio de Janeiro: Elsevier, 2007. p. 103-123. ${ }^{30}$ COSTA, Emílio Carlos Dantas. Op. Cit. In SADDI, Jairo. Intervenção..., p. 77.

31 Informações colhidas no sítio eletrônico do Banco Central do Brasil. Disponível em <http://www.bcb.gov.br/?PROER>. Acesso em 08 fev. 2014.

32 SIQUEIRA, Francisco José de. O Papel do Banco Central no processo de Intervenção e Liquidação Extrajudicial. In SADDI, Jairo. Intervenção..., p. 89.

${ }^{33}$ Idem.

34 Informações colhidas no sítio eletrônico do Banco Central do Brasil. Disponível em <http://www.bcb.gov.br/?PROER>. Acesso em 07 fev. 2014.
} 

SANEAMENTO BANCÁRIO NO BRASIL

Dentro dessas perspectivas, especialmente diante do grande número de instituições em situação deficitária, percebeu-se que a promoção de medidas de intervenção e liquidação (fundadas na Lei 6.024/1974), com a paralisação imediata das atividades bancárias, notadamente em instituições de grande porte (too big tofail), tenderia a implicar danos severos ao funcionamento do mercado financeiro, na medida em que estancaria a intermediação de recursos aos setores produtivos e, ainda, bordejaria afluxos de capital para fora dos bancos eventualmente saudáveis, como resultado das corridas bancárias.

Além do mais, nos procedimentos administrativos de intervenção e liquidação extrajudicial, os credores das instituições liquidandas, no mais das bezes, têm de esperar pacientemente a apuração dos ativos da massa e o pagamento dos passivos, de acordo com a respectiva classificação creditícia, situação a desnudar, mais uma vez, os danos socioeconômicos de procedimentos liquidatórios ${ }^{35}$ à vista da complexidade e da lentidão desses processos ${ }^{36}$.

Portanto, "não havia alternativa milagrosa: ou o Governo Federal deixava que o mercado sofresse o impacto da intervenção ou liquidação, ou apresentava um programa de reorganização das empresas em estado de dificuldade, sob pena de acontecer uma quebradeira em cadeia" 37.

Eis aí, em grande medida e consoante se anotará em tópico subsequente, a ocasião externa ao sistema jurídico a permitir e a ensejar a abertura do ordenamento objetivo (Direito Positivo), como forma de, identificando os fatores econômicos necessários à modificação de suas

\footnotetext{
35 “A liquidação de um banco é seu fechamento definitivo. Contas seguradas são pagas imediatamente e, acima de certo limite, os depósitos são convertidos em créditos contra a massa e considerados antecipadamente vencidos, valendo aqui o princípio legal do par conditio creditorum, ou seja, todos os direitos e interesses relativos ao acervo da entidade liquidanda devem receber as condições igualitárias de tratamento. Esse é o modelo que mais certamente pode gerar quebra de confiança e precipitar crises bancárias". SADDI, Jairo. Crise e Regulação Bancária: navegando mares revoltos. São Paulo: Textonovo, 2001. p. 231.

36 "A crítica mais comum à Lei $\mathrm{n}^{\circ}$ 6.024/74 tem a ver com a celeridade e a eficiência dos processos de liquidação, que se arrastam por muitos anos. Porém, a experiência recente com as operações ao amparo do PROER, (...), relativizou essas preocupações, pois os benefícios decorrentes da possibilidade de engendrar a cisão entre o 'banco ruim' (...) e o 'banco bom' - que permanece em funcionamento, com outra bandeira, outra gestão e outros controladores, assim salvaguardando depositantes e investidores parecem superar fartamente os custos decorrentes da demora na solução para o 'banco ruim'”. FRANCO, Gustavo H. B.; ROSMAN, Luiz Alberto C. A responsabilidade ilimitada em instituições financeiras no Brasil. Antecedentes, Experiência e Considerações. In CARNEIRO, Dionísio Dias; BOLLE, Monica Baumgarten de (Org.). A reforma do Sistema Financeiro Americano: nova arquitetura internacional e o contexto regulatório brasileiro. Rio de Janeiro: LTC, 2010. p. 86.

${ }^{37}$ ABRÃO, Nelson. Direito Bancário. 14. ed. São Paulo: Saraiva, 2000. p. 365.
} 

SANEAMENTO BANCÁRIO NO BRASIL

estruturas internas ${ }^{38}$, o sistema jurídico viabilizar a filtragem dos elementos do sistema econômico pela via do chamado acoplamento estrutural ${ }^{39}$.

\section{A ABERTURA DO SISTEMA JURÍDICO}

Claus-Wilhelm Canaris traça uma primeira diferença entre os sistemas jurídicos abertos e fechados. Aponta que estes (cerrados) seriam resultado de uma ordem jurídica pautada na codificação, enquanto aqueles seriam resultado de uma ordem jurídica edificada casuisticamente e apoiada fundamentalmente na jurisprudência.

No entanto, segundo Canaris, haveria outra forma de identificar e discernir os sistemas jurídicos em abertos e fechados a partir da apuração de três vertentes: a incompleitude, a capacidade de evolução e a modificabilidade do sistema. Nesse viés, o sistema jurídico pautado na codificação poderia ser, independentemente disso, aberto ${ }^{40}$. No Direito, separam-se, assim, duas modalidades de abertura: a abertura do sistema científico (sistema de proposições doutrinárias da Ciência do Direito) e a abertura do sistema objetivo (Direito positivo).

$\mathrm{Na}$ primeira hipótese, tem-se que as alterações do sistema derivam basicamente da provisoriedade do conhecimento científico, de modo que "o jurista, como qualquer cientista, deve estar sempre preparado para pôr em causa o sistema até então elaborado e para o alargar ou modificar, com base numa melhor consideração" ${ }^{41}$.

No sistema objetivo, por outro lado, a porosidade resultaria da modificação dos valores fundamentais da ordem jurídica, eis que "o Direito Positivo, mesmo quando consista numa ordem jurídica assente na ideia de codificação, é, notoriamente, susceptível de aperfeiçoamento, em vários campos ${ }^{42}$ ", de sorte que "o sistema, como unidade de sentido,

\footnotetext{
38 “No plano dos acoplamentos estruturais, há possibilidades armazenadas (ruídos) no meio, que podem ser transformadas pelo sistema; portanto, mediante o acoplamento estrutural, o sistema desenvolve, por um lado, um campo de indiferença e, por outro, faz com que haja uma canalização de causalidade que produz efeitos que são aproveitados pelo sistema." LUHMANN, Niklas. Introdução à Teoria dos Sistemas, p. 131. 39 "Esse acoplamento serviria à promoção e filtragem de influências e instigações recíprocas entre sistemas autônomos diversos, de maneira duradoura, estável e concentrada, vinculando-os no plano de suas respectivas estruturas, sem que nenhum desses sistemas perca a sua respectiva autonomia." NEVES, Marcelo. Transconstitucionalismo, p. 35.

${ }^{40}$ CANARIS, Claus-Wilhelm. Pensamento sistemático e conceito de sistema na ciência do Direito. 2. ed. Lisboa: Fundação CalousteGulbenkian, 1996. p. 104.

${ }^{41}$ Ibidem, p. 106.

42 Ibidem, p. 107.
} 
compartilha uma ordem jurídica no seu modo de ser, isto é, que tal como esta, não é estático, mas dinâmico, assumindo pois a estrutura da historicidade"43.

Nesse sentido, o conjunto de fatores financeiros, sociais e políticos e sucedidos na década de 1990 fez com que o sistema jurídico objetivo, sensível às mudanças fáticoeconômicas, filtrasse as ocorrências externas e as incorporasse ao ordenamento interno. Eis que o acoplamento estrutural permitiu uma abertura cognitiva do sistema jurídico sem deixar de operar, autonomamente, a partir dos seus pressupostos internos.

0 primeiro exemplo da porosidade do sistema jurídico-normativo em relação às aspirações de política macroeconômica pode ser descrito com a criação do programa de estabilização monetária, consolidado com a edição da Lei n 8.880, de 27 de maio de 1994, e da Lei $n^{\circ}$ 9.069, de 29 de junto de 1995, as quais oportunizaram notórios avanços na reestruturação do sistema financeiro, na estabilização da moeda e na reorganização das instituições bancárias com elevado grau de desencaixe entre ativos e passivos ou com desconexa exposição a riscos.

Em adição, notadamente sob o ponto de vista das instituições financeiras submetidas a regimes especiais (intervenção administrativa, liquidação extrajudicial ou administração temporária), há igualmente se ser destacada a edição da Lei 9.447, de 14 de março de 1997, cuja análise denota de substancial proeminência no contexto aqui proposto.

A notoriedade das severas deficiências do sistema bancário nacional foi realçada com a decretação de intervenção do Banco Econômico S/A em 11 de agosto de $1995^{44}$. Tal situação fez com que o Estado propusesse (e o sistema jurídico encapasse) novas formas de reorganização e reestruturação das instituições financeiras, especialmente daquelas consideradas insolventes. A partir da criação do PROER, em novembro de 1995, foram compreendidas novas linhas especiais de assistência financeira ${ }^{45}$, além da flexibilização do atendimento dos limites operacionais aplicáveis às instituições financeiras deficitárias, bem como o diferimento dos gastos relativos aos custos, despesas e outros encargos com a reestruturação, reorganização ou modernização de

\footnotetext{
${ }^{43}$ Ibidem, p. 108.

${ }_{44}^{4}$ Por meio dos Atos Presinos 352, 353, 354 e 355, do Banco Central do Brasil.

45 "O acesso às linhas de crédito do PROER foi condicionada à expressa autorização do Banco Central, concedida caso a caso, tendo como pré-requisito básico a mudança de controlador. Ou seja, apesar dos alguns financiamentos vultosos terem sido formalmente concedidos a bancos insolventes, sob intervenção, os recursos destinaram-se sempre a viabilizar a proteção de seus depositantes, pela transferência de sua parte saudável a um novo grupo controlador". LUNDBERG, Eduardo. Saneamento do Sistema Financeiro: a experiência brasileira dos últimos 25 anos. In SADDI, Jairo. Intervenção..., p. 60.
} 

SANEAMENTO BANCÁRIO NO BRASIL

instituições financeiras $^{46}$. Foi determinada, ainda, a liberação de recursos do recolhimento compulsório/encaixe obrigatório sobre recursos à vista para aquisição de Certificados de Depósitos Bancários (CDB) de emissão de instituições participantes do PROER ${ }^{47}$.

Ao longo do tempo, outros dois modelos de programas foram implementados: um, destinado aos bancos públicos estaduais (Proes ${ }^{48}$ ), criado em 1996; outro, o denominado Programa de Fortalecimento das Instituições Financeiras Federais, por sua vez implantado em 2001. Especificamente no âmbito do Programa de reestruturação dos bancos estaduais, facultouse à União Federal, a seu livre alvedrio: adquirir a instituição financeira estadual intuindo privatizá-la ${ }^{49}$ ou extingui-la, por meio do pagamento em títulos públicos; financiar o processo de extinção da entidade ou de sua transformação em instituição não financeira ou agência de fomento; financiar os ajustes prévios necessários à privatização da empresa ou prestar garantia a financiamento concedido pelo Banco Central; e adquirir créditos da instituição bancária junto a seu controlador, ou a entidades por ele controladas, e refinanciar os créditos assim adquiridos $^{50}$.

Considerado o mais importante deles, o PROER adotava um modelo básico bastante relevante. Partindo do pressuposto de que a ideia precípua consistia em assegurar liquidez e solvência do Sistema Financeiro e em resguardar os interesses de depositantes e investidores, optou-se pela reestruturação bancária com a continuação das atividades então exercidas pela instituição insolvente, em benefício da coletividade ${ }^{51}$.

\footnotetext{
${ }^{46}$ Perscrutando o assunto, Gilberto Tadeu Lima assinala que os recursos envolvidos "seriam provenientes dos depósitos compulsivos recolhidos pelas próprias instituições integrantes do sistema financeiro, não comprometendo o orçamento fiscal". LIMA, Gilberto Tadeu. Op. Cit. In SOBREIRA, Rogério (Org.). Op. Cit., p. 203.

${ }^{47}$ Artigo $2^{\circ}$ da Resolução 2.208 do BACEN.

48 De maneira geral, o Proes tencionou resolver os problemas de liquidez e deterioração patrimonial observados nos bacos estaduais, privatizando algumas instituições e liquidando outras. Para Eduardo Lundberg: "A solução definitiva para os bancos estaduais só veio com a Medida Provisória 1.514, de 07.08.96, que autorizou o governo federal a financiar a privatização, extinção ou transformação dos bancos estaduais e, mais importante, autorizou também a aquisição dos créditos de governos estaduais e de suas empresas junto a seus bancos. Com a compra e refinanciamento pela União dessas dívidas, deu-se solução simultânea para dois problemas: bancos e finanças públicas". LUNDBERG, Eduardo. Saneamento... In SADDI, Jairo. Intervenção..., p. 59.

49 As receitas das privatizações estão disponíveis no sítio eletrônico do Banco Central do Brasil: www.bacen.gov.br.

${ }^{50}$ SIQUEIRA, Francisco José de. Op. Cit. In SADDI, Jairo. Intervenção..., p. 115.

51 Sobre o assunto, consigna Eduardo Lundberg: "Para que uma reestruturação bancária tenha maiores chances de sucesso o ideal é a recapitalização do banco e a mudança no controle societário e na alta administração da sociedade. Os objetivos de uma reestruturação bancária podem ser alcançados sob
} 

SANEAMENTO BANCÁRIO NO BRASIL

Com efeito, o Banco Central adotou o molde de cindir a instituição em duas partes, uma delas considerada superavitária (ou positiva, com ativos reais potencialmente lucrativos) e a outra subentendida como deficitária (cuja aferição potencial dos ativos não permitisse pressupor a reorganização da atividade).

Cuidou-se, especificamente, de um modelo de cisão goodbankbadbank, no qual o segmento interno da instituição que revelasse ativos importantes, ou positivamente relevantes, depois de saneado por meio das operações do PROER, seria transferido a outra instituição financeira, eventualmente até mesmo estrangeiras ${ }^{52}$, a fim de possibilitar a manutenção do exercício da atividade e o menor prejuízo possível aos investidores e poupadores da instituição. Por outro lado, a parte deficiente, cujos saldos contábeis se mostrassem negativos e virtualmente irrecuperáveis, seria submetida aos procedimentos de intervenção ou liquidação extrajudicial, nos termos da legislação regencial ${ }^{53}$.

diferentes arranjos. São dois os modelos básicos utilizados em reestruturações: o modelo de cisão da parte saudável (goodbank/badbank) e o modelo da aquisição (purchaseandassumption), assumindo-se eventuais prejuízos. Em ambos os casos, minimizam-se as perdas impostas ao sistema financeiro, aos clientes e empregados, permitindo também a negociação do valor intangível do negócio (goodwill), que seria perdido com a liquidação". LUNDBERG, Eduardo. Rede de proteção e saneamento do sistema bancário. In SADDI, Jairo. Intervenção..., p. 49.

52 "Com o advento da Carta Política de 1988, eis que, em razão do que estatui o artigo 52 do Ato das Disposições Constitucionais Transitórias, ficou suspensa a instalação de novas agências de instituições bancárias domiciliadas no exterior, bem como o aumento da participação estrangeira no capital das instituições com sede no País, enquanto não fossem estabelecidas condições especificas mediante lei complementar, com ressalva das hipóteses de autorização resultantes de acordos internacionais de reciprocidade ou de interesse do governo brasileiro. Mais tarde, no entanto, o Presidente da República aprovou a Exposição de Motivos no 311, de 23 de agosto de 1995, apresentada pelo Ministro da Fazenda, que instituiu diretrizes para aplicação da ressalva admitida naquele preceito constitucional, assim permitindo a volta da participação do capital externo na indústria bancária do País, especialmente visando à privatização de bancos estaduais e à reestruturação de empresas com dificuldades financeiras ou submetidas a medidas especiais." SIQUEIRA, Francisco José de. Op. Cit. In SADDI, Jairo. Intervenção..., p. 90.

53 “No Proer, o mais importante daqueles programas, o modelo básico adotado era o de uma divisão da instituição que apresentava problemas em parcelas, o goodbank e o badbank. A primeira parcela, composta pelos depósitos e por ativos que se mostrassem mais interessantes, era adquirida por um terceiro, enquanto a segunda seria objeto de liquidação extrajudicial. A implementação desse mecanismo envolveu, como aliás não é raro que ocorra em matéria de regulação sistêmica, a estruturação de um arcabouço legal adequado (contido, inicialmente, na Medida Provisória instituidora do programa), atribuindo claramente responsabilidades aos administradores das instituições envolvidas e afastando expressamente determinados direitos dos acionistas minoritários”. YAZBEK, Otávio. Op. Cit., p. 280. 

SANEAMENTO BANCÁRIO NO BRASIL

Tal possibilidade de reorganização societária compulsória veio expressamente descrita no artigo $5^{\circ}$ da Lei $9.447 / 97^{54}$. Nessa trilha, assevera Eduardo Lundberg que a vantagem desse conjunto de medidas teria sido a "de não beneficiar os acionistas e administradores do banco insolvente mediante a negociação da parte saudável, que pode continuar funcionando normalmente" 55 , de sorte que "as ações e quaisquer outros direitos societários não são objeto de negociação, mas apenas a parte saudável que, da mesma forma que numa liquidação ordinária, teria de ser negociada para fazer face ao pagamento dos credores e depositantes" ${ }^{\text {. }}$.

Além do mais, sob o ponto de vista econômico, "as fusões e aquisições bancárias proporcionaram um aumento na eficiência de intermediação dos bancos compradores, possivelmente decorrentes de aprimoramentos no gerenciamento operacional e de cortes nos custos administrativos e de pessoal” ${ }^{, 57}$.

De maneira geral, a instituição do PROER, especialmente a partir da edição da Lei 9.447/97, legitimou a intervenção estatal de forma mais profusa e verticalizada, conduzida pela concretização de instrumentos jurídicos alinhados com o objetivo último de sanear o Sistema Financeiro e sancionar as más práticas de gestão administrativa, utilizando-se mecanismos de ingerência direta nas instituições insolventes, com grande intervenção nos direitos civis/patrimoniais das empresas, consubstanciada, sobretudo, na transferência de ativos positivos a outras instituições ${ }^{58}$.

\footnotetext{
${ }^{54}$ Art. $5^{\circ}$ Verificada a ocorrência de qualquer das hipóteses previstas nos arts. $2^{\circ}$ e 15 da Lei $n^{\circ} 6.024$, de 1974 , e no art. $1^{\circ}$ do Decreto-lei $n^{\circ} 2.321$, de 1987, é facultado ao Banco Central do Brasil, visando assegurar a normalidade da economia pública e resguardar os interesses dos depositantes, investidores e demais credores, sem prejuízo da posterior adoção dos regimes de intervenção, liquidação extrajudicial ou administração especial temporária, determinar as seguintes medidas:

I - capitalização da sociedade, com o aporte de recursos necessários ao seu soerguimento, em montante por ele fixado;

II - transferência do controle acionário;

III - reorganização societária, inclusive mediante incorporação, fusão ou cisão.

Parágrafo único. Não implementadas as medidas de que trata este artigo, no prazo estabelecido pelo Banco Central do Brasil, decretar-se-á o regime especial cabível.

${ }_{55}^{55}$ LUNDBERG, Eduardo. Rede de... In SADDI, Jairo. Intervenção..., p. 49.

${ }^{56}$ Idem.

${ }^{57}$ FARIA, João Adelino de; PAULA, Luiz Fernando de; MARINHO, Alexandre. Eficiência do Setor Bancário Brasileiro: a experiência recente das fusões e aquisições. In PAULA, Luiz Fernando de; OREIRO, José Luís (Org.). Sistema Financeiro: uma análise do setor bancário brasileiro. Rio de Janeiro: Elsevier, 2007. p. 151.

${ }^{58}$ Gentil Corazza sustenta que o Proer "conferiu ao banco central os instrumentos legais de atuação preventiva e de liquidação das instituições insolventes", representando "um mecanismo de estimulo à reorganização das instituições financeiras, seja mediante fusões, incorporações, cisões, desmobilizações ou qualquer outra forma de reestruturação que thes possibilite alcançar padrões de eficiência e
} 

SANEAMENTO BANCÁRIO NO BRASIL

Sob o ponto de vista estritamente jurídico, apenas com a implementação de artefatos legais legitimadores foi possível fortalecer o Banco Central do Brasil para promover, efetivamente e sem fragilidades ou rupturas ulteriores, a mais profunda onda de saneamento e reestruturação das instituições financeiras privadas.

Logo no início de sua instauração, foram concretizadas reestruturações em quatro instituições financeiras importantes, mediante a viabilização do modelo de cisão ‘banco bom' e 'banco ruim', ${ }^{59}$, permitindo que os circuitos financeiros não fossem obstruídos abruptamente, já que os depósitos bancários mantiveram-se exigíveis a qualquer tempo, bem como viabilizando que ativos potencialmente favoráveis fossem incorporados por instituições saudáveis. Ao todo, ao longo do Programa, foram realizadas oito operações de fusões e aquisições, modificando substancialmente a estrutura do mercado bancário nacional ${ }^{60}$.

Divisou-se, assim, que se mantivessem atuando e operando financeiramente ativas no Sistema apenas as instituições dotadas de elevado grau de liquidez, saúde econômica e solidez patrimonial ${ }^{61}$.

competitividade". CORAZZA, Gentil. Os dilemas da supervisão bancária. In SOBREIRA, Rogério (Org.). Regulação Financeira e Bancária. São Paulo: Atlas, 2005. p. 92.

59“'Desde o início da crise bancária de 1995, o Banco Central 'reestruturou' 4 bancos privados (3 grandes e um médio - o Banorte) utilizando o modelo da cisão ('goodbank/badbank') permitido pela nova legislação. Quase que simultaneamente à criação do PROER foi promovida a venda da parte saudável do Banco Nacional ao Unibanco (novembro de 1995), que foi imediatamente incorporado ao banco comprador. A seguir, em abril de 1996, deu-se solução ao Banco Econômico, cuja parte saudável foi vendida ao grupo Excel que, fundida ao banco daquele conglomerado, resultou no Excel-Econômico. Para as soluções destes dois bancos, o Banco Central concedeu aos bancos em regime especial (os 'badbank') financiamento PROER para viabilizar a formação de um conjunto de ativos e passivos de igual valor (o 'goodbank' objeto da cisão). Tal financiamento foi concedido mediante garantias em "moedas podres", basicamente créditos contra o Fundo de Compensação de Variações Salariais (FCVS) das próprias instituições financeiras". LUNDBERG, Eduardo. Rede de... In SADDI, Jairo. Intervenção..., p. 49.

${ }^{60}$ MAIA, Geraldo Vilar Sampaio. Reestruturação Bancária no Brasil: o caso Proer. Notas Técnicas do Banco Central do Brasil. Informações e dados estatísticos disponíveis em <http://www.bcb.gov.br/pec/notastecnicas/port/2003nt38ReestrutBancBrasilp.pdf> Acesso em 10 jan. 2013.

61 Resultando desse movimento de consolidação bancária, pode-se observar uma "diminuição na quantidade de instituições, um aumento no grau de concentração bancária na maioria dos países, uma diminuição no número dos trabalhadores no setor (devido aos avanços tecnológicos e às fusões e aquisições), um aumento na participação relativa das receitas não juros no total das receitas bancárias e finalmente, um declínio nas margens liquidas de juros dos bancos devido ao aumento da competição no mercado". FARIA, João Adelino de; PAULA, Luiz Fernando de; MARINHO, Alexandre. Op. Cit. In PAULA, Luiz Fernando de; OREIRO, José Luís (Org.). Op. Cit., p. 127. 

SANEAMENTO BANCÁRIO NO BRASIL

Não se deve olvidar, no entanto, que "polpudas somas foram gastas pelo Governo Federal, vários bilhões de reais, simplesmente com o desiderato de permitir a sobrevida das empresas em crise, tornando-as aptas à agregação societária” ${ }^{02}$. Residiu, talvez aqui, um dos pontos que se pode considerar negativo: a utilização de recursos derivados do contribuinte para viabilizar o saneamento do Sistema Financeiro. Inobstante a ideia fosse a salvaguarda do conjunto - e não de alguma instituição individualmente considerada -, fato é que consideráveis somas de dinheiro público ${ }^{63}$ foram utilizadas na tentativa de preservar o novo modelo de País que estava sendo implantado (fundado, basicamente, na estabilização monetária e na desvinculação do Estado como monopolizador de alguns serviços públicos). Além disso, muito se questionou a respeito da transparência na utilização dos recursos, bem assim acerca da ausência ou subjetividade de critérios de aporte, já que ambos dessumiam análise discricionária do Banco Central ${ }^{64}$.

Ao que importa inferir, neste breve estudo, é que, no contexto dos eventos ocorridos em meados da década de 1990, observou-se como o sistema jurídico abriu-se aos anseios econômicos advindos da macropolítica de reestruturação do sistema financeiro nacional e, sobretudo, dos programas de estabilização monetária e abertura econômica do País.

Adicione-se a isso, por relevante, outra proeminente invenção: o Fundo Garantidor de Créditos (FGC), criado em $1995^{65}$ sob o timbre de associação civil sem fins econômicos e a partir do custeio direto derivado de contribuições dos próprios agentes financeiros a ele vinculados, foi inicialmente concebido como mecanismo exógeno de seguro dos depósitos bancários, limitado a

\footnotetext{
${ }^{62}$ ABRÃO, Nelson. Op. Cit., p. 368.

${ }^{63}$ Os números variam e os custos efetivos podem se alterar ao longo do tempo, pois somente ao fim dos processos liquidatórios será possível aferir com exatidão as despesas totais em relação aos créditos pagos. Porém, dados colhidos na Nota Técnica do Banco Central, de junho de 2003, estimam que, ao todo, as operações do Proer custaram R\$ 20,4 bilhões, aproximadamente 2,7\% do PIB médio do Brasil em 1995, 1996 e 1997. Até junho de 2003, o saldo sem cobertura correspondia a R\$ 8,5 bilhões. MAIA, Geraldo Vilar Sampaio. Op. Cit. Informações constantes no sítio do Banco Central do Brasil. Disponível em <http://www.bcb.gov.br/pec/notastecnicas/port/2003nt38ReestrutBancBrasilp.pdf>. Acesso em 10 jan. 2013.

${ }^{64}$ Sobre o tema: “O PROER foi criado com o objetivo claro, mas não claramente divulgado, de evitar a quebra de instituições financeiras brasileiras que mostravam - já em meados de 1995 - uma situação de insolvência que comprometia a saúde do sistema como um todo". COSTA, Ana Carla Abraão. Fundo Garantidor de Créditos - Estrutura e contexto de criação. Disponível em <http://www.fgc.org.br/upload/Academico/FGC_Estrutura_e_Contexto_de_Criacao.pdf>. Acesso em 11 jan. 2013.

${ }^{65}$ Por meio da Resolução 2.197, de 31.08.1995, o Conselho Monetário Nacional autorizou a constituição de entidade privada, sem fins lucrativos, destinada a administrar mecanismos de proteção a titulares de créditos contra instituições financeiras.
} 
valores prefixados ${ }^{66}$, porém sua atuação restou maturada e ampliada durante os anos que se passaram depois de seu nascedouro, constituindo, hodiernamente, um essencial engenho de proteção ao setor bancário nacional.

Explica-se, em suma: o Conselho Monetário Nacional, em 24 de maio de 2012, editou a Resolução $n^{\circ}$ 4.087, alterando o Estatuto de formação do FGC, amplificando normativamente as suas atribuições. Nesse sentido, inseriu-se na listagem de atribuições a possibilidade de contratação de operações de assistência ou de suporte financeiro, incluindo operações de liquidez com as instituições associadas, diretamente ou por intermédio de empresas indicadas.

Estas operações de salvaguarda financeira das instituições podem ser contratadas, inclusive, com o objetivo de promover a transferência do controle acionário, a transformação, a incorporação, a fusão, a cisão ou outras formas de reorganização societária legalmente admitidas $^{67}$, tal e qual anteriormente foram operadas nas moções de reestruturação empenhadas nos anos 1995/1997 (goodbank/badbank) - a diferença, agora, não está na premissa, mas na fonte dos recursos.

\section{CONCLUSÃO}

Com apoio teórico na Teoria dos Sistemas de NiklasLuhmann, fez-se visitar rapidamente os conceitos de autopoiese e de acoplamento estrutural, a partir dos quais se pode identificar os mecanismos de recepção de informações (e de demandas) entre os diversos sistemas sociais, assim como o processo de filtragem cognitiva interna e de manutenção da autonomia operacional. Procurou-se compreender, nessa linha, que, na teoria sistêmica de Luhmann, o acoplamento estrutural é apresentado como um mecanismo de comunicação entre dois sistemas autônomos.

Alicerçado nesse marco doutrinário, objetivou-se compreender, dentro de um específico e substancialmente importante momento político-econômico brasileiro, a forma pela qual o sistema jurídico teve de adaptar-se para ouvir os ruídos do meio (especialmente advindas do sistema econômico) e, assim, após o processo de decantamento dessas informações, abrir-se para inseri-los dentro do ordenamento jurídico interno, a fim de legitimar e possibilitar diversas

\footnotetext{
${ }^{66}$ Atualmente, o limite de cobertura de seguros depósitos é de $\mathrm{R} \$ 250.000,00$ (duzentos e cinquenta mil reais). Disponível em <http://www.fgc.org.br/?ci_menu=20\&conteudo=1>. Acesso em 24 set. 2014.

${ }^{67}$ Artigo $4^{\circ}$, parágrafo $1^{\circ}$, da Resolução 4.087 do CMN.
} 

SANEAMENTO BANCÁRIO NO BRASIL

ações estatais, notadamente realizadas pelo Banco Central do Brasil, visando a salvaguardar a estabilidade e a regularidade do funcionamento do Sistema Financeiro Nacional.

Fundamentalmente após a edição das legislações que viabilizaram a implementação do Plano Real e, em especial, da Lei 9.447/97, intentou-se verificar em que medida e sob quais panoramas fático-sociais o sistema jurídico nacional, observando os movimentos e as oscilações econômicas do sistema bancário, encampou uma série de disposições normativas hábeis a permitir que o Banco Central alterasse a forma de intervenção direta nas instituições financeiras em situação de insolvência.

Assim, com o escopo de evitar a paralisação imediata das atividades de inúmeras instituições insolventes de grande porte, situação tendente a implicar mais danos do que benefícios tendo em vista a possibilidade de colapso sistêmico, houve maturação de procedimentos atinentes à cisão bancária e, por assim dizer, de reorganização compulsória da respectiva sociedade empresária, liquidando-se a parte ruim e alienando-se a parte boa a quem dela pudesse servir-se à manutenção das atividades bancárias.

Por fim, a criação do Fundo Garantidor de Créditos - cuja natureza jurídica é associação civil sem fins econômicos -, custeado por contribuições diretas das próprias instituições participantes, permitiu que o sistema jurídico igualmente traduzisse normativamente a necessidade de readaptação da forma de saneamento bancário, mormente pelo fato de polpudas somas de dinheiro público terem sido dispendidas quando da formatação dos Programas de Reestruturação do sistema Bancário na década de 1990.

\section{REFERÊNCIAS}

ABRÃO, Nelson. Direito Bancário. 14. ed. São Paulo: Saraiva, 2000.

BRASIL. Lei n. ${ }^{\circ} 8.880$ de 27 de maio de 1994. Dispõe sobre o Programa de Estabilização Econômica e o Sistema Monetário Nacional, institui a Unidade Real de Valor (URV) e dá outras providências. Disponível em <http://www.planalto.gov.br/ccivil_03/leis/L8880.htm>. Acesso em 29 mai. 2014.

BRASIL. Lei n. ${ }^{\circ} 9.069$ de 29 de junho de 1995. Dispõe sobre o Plano Real, o Sistema Monetário Nacional, estabelece as regras e condições de emissão do REAL e os critérios para conversão das obrigações para o REAL. Disponível em <http://www.planalto.gov.br/ccivil_03/leis/L9069.htm>. Acesso em 29 mai. 2014. 

SANEAMENTO BANCÁRIO NO BRASIL

BRASIL. Lei n. ${ }^{\circ} 9.447$ de 14 de março de 1997. Dispõe sobre a responsabilidade solidária de controladores de instituições submetidas aos regimes de que tratam a Lei $n^{\circ} 6.024$, de 13 de março de 1974, e o Decreto-lei n 2.321, de 25 de fevereiro de 1987; sobre a indisponibilidade de seus bens; sobre a responsabilização das empresas de auditoria contábil ou dos auditores contábeis independentes; sobre privatização de instituições cujas ações sejam desapropriadas, na forma do Decreto-lei $n^{\circ} 2.321$, de 1987. Disponível em <http://www.planalto.gov.br/ccivil_03/leis/L9447.htm>. Acesso em 29 mai. 2014.

CANARIS, Claus-Wilhelm. Pensamento sistemático e conceito de sistema na ciência do Direito. 2. ed. Lisboa: Fundação CalousteGulbenkian, 1996.

CARVALHO, Fernando J. Cardim de. Regulação Prudencial na Encruzilhada: depois de Basiléia II, o Dilúvio? In PAULA, Luiz Fernando de; OREIRO, José Luís (Org). Sistema Financeiro: uma análise do setor bancário brasileiro. Rio de Janeiro: Elsevier, 2007. p. 155-167.

COELHO, Fábio Ulhoa. Assunção de ativos e transferência de passivos na recuperação da empresa financeira: a reorganização externa. Revista de Direito Bancário e do Mercado de Capitais e da Arbitragem, São Paulo, ano 4, n 11, p. 39-47, jan./mar. 2001.

CONSELHO MONETÁRIO NACIONAL. Resolução $n^{\circ} 4.087$ de 24 de maio de 2012 . Altera e consolida as normas que dispõem sobre o estatuto e o regulamento do Fundo Garantidor de Créditos (FGC). Disponível em <http://www.bcb.gov.br/pre/normativos/res/2012/pdf/res_4087_v2_L.pdf.>. Acesso em 12 mai. 2014.

CONSELHO MONETÁRIO NACIONAL. Resolução n 2.211 de 16 de novembro de 1995. Aprova o estatuto e o regulamento do Fundo Garantidor de Créditos. Disponível em <http://www.bcb.gov.br/pre/normativos/res/1995/pdf/res_2211_v3_P.pdf.>. Acesso em 12 mai. 2014.

CORAZZA, Gentil. Os dilemas da supervisão bancária. In SOBREIRA, Rogério (Org.). Regulação Financeira e Bancária. São Paulo: Atlas, 2005. p. 82-95.

COSTA, Ana Carla Abraão. Fundo Garantidor de Créditos - Estrutura e contexto de criação. Disponível em

<http://www.fgc.org.br/upload/Academico/FGC_Estrutura_e_Contexto_de_Criacao.pdf > Acesso em 11 jan. 2013.

COSTA, Emílio Carlos Dantas. Supervisão Bancária: conceitos gerais. In SADDI, Jairo. Intervenção e liquidação no sistema financeiro nacional - 25 anos da Lei 6.024/74. São Paulo: Textonovo, 1999. p.71-86.

FARIA, João Adelino de; PAULA, Luiz Fernando de; MARINHO, Alexandre. Eficiência do Setor Bancário Brasileiro: a experiência recente das fusões e aquisições. In PAULA, Luiz Fernando de; 
OREIRO, José Luís (Org.). Sistema Financeiro: uma análise do setor bancário brasileiro. Rio de Janeiro: Elsevier, 2007. p. 125-154.

FERGUSON, Niall. A ascensão do dinheiro: a história financeira do mundo. São Paulo: Planeta, 2009.

FRANCO, Gustavo H. B.; ROSMAN, Luiz Alberto C. A responsabilidade ilimitada em instituições financeiras no Brasil. Antecedentes, Experiência e Considerações. In CARNEIRO, Dionísio Dias; BOLLE, Monica Baumgarten de (Org.). A reforma do Sistema Financeiro Americano: nova arquitetura internacional e o contexto regulatório brasileiro. Rio de Janeiro: LTC, 2010. p. 8594.

LEITÃO, Mirian. Saga Brasileira: a longa luta de um povo por sua moeda. Rio de Janeiro: Record, 2011.

LIMA, Fernando Rister Sousa. Constituição Federal: acoplamento estrutural entre os sistemas político e jurídico. Revista Eletrônica de Direitos Fundamentais e Democracia da Unibrasil, Volume 4, 2008.

LIMA, Gilberto Tadeu. Evolução Recente da Regulação Bancária no Brasil. In SOBREIRA, Rogério (Org.). Regulação Financeira e Bancária. São Paulo: Atlas, 2005. p. 185-209.

LUHMANN, Niklas. Introdução à Teoria dos Sistemas. Petropolis/RJ: Editora Vozes, 2009. . Introducción a lateoría de sistemas. Versão espanhola Javier Torres Nafarrate. México: Universidad Ibero Americana, 1996.

LUNDBERG, Eduardo. Rede de proteção e saneamento do sistema bancário. In SADDI, Jairo. Intervenção e liquidação no sistema financeiro nacional - 25 anos da Lei 6.024/74. São Paulo: Textonovo, 1999. p. 29-51.

MAIA, Geraldo Vilar Sampaio. Reestruturação Bancária no Brasil: o caso Proer. Notas Técnicas do Banco Central do Brasil. Informações e dados estatísticos disponíveis em <http://www.bcb.gov.br/pec/notastecnicas/port/2003nt38ReestrutBancBrasilp.pdf> Acesso em 10 jan. 2013.

NEVES, Marcelo. Entre Themis e Leviatã: uma relação difícil. São Paulo: Martins Fontes, 2006. Transconstitucionalismo. São Paulo: Editora Martins Fontes, 2009. 
ISSN 1981-3694

(DOI): $10.5902 / 1981369415684$

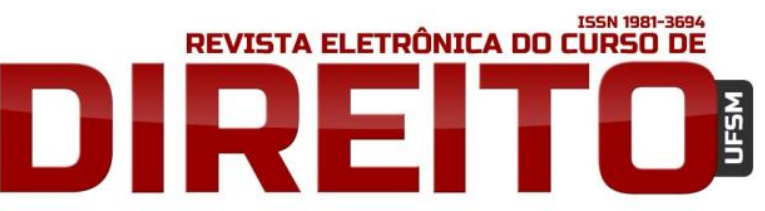

O ACOPLAMENTO ESTRUTURAL E O MOVIMENTO DE SANEAMENTO BANCÁRIO NO BRASIL

NEVES, Rômulo Figueira. Acoplamento estrutural, fechamento operacional e processos sobrecomunicativos na teoria dos sistemas sociais de NiklasLuhmann. São Paulo, 2005. Dissertação de Mestrado (Mestrado em Sociologia) Universidade de São Paulo.

SADDI, Jairo. Crise e Regulação Bancária: navegando mares revoltos. São Paulo: Textonovo, 2001.

O Poder e o Cofre: repensando o Banco Central. São Paulo: Textonovo, 1997.

SIQUEIRA, Francisco José de. O Papel do Banco Central no processo de Intervenção e Liquidação Extrajudicial. In SADDI, Jairo. Intervenção e liquidação no sistema financeiro nacional - 25 anos da Lei 6.024/74. São Paulo: Textonovo, 1999. p. 87-120.

TRINDADE, André. Para entender Luhmann: e o direito como sistema autopoiético. Porto Alegre: Livraria do Advogado, 2008.

YAZBEK, Otávio. Regulação do Mercado Financeiro e de Capitais. 2. ed. Rio de Janeiro: Elsevier, 2009.

Recebido em: 25/09/2014 / Aprovado em: 20/01/2015 